\title{
Building Strategic University-Industry Partnerships and Sustainable Growth: The Lebanese Experience
}

\author{
Abir R. Takieddine ${ }^{1}$ \\ ${ }^{1}$ Faculty of Economic Sciences \& Business Administration, Lebanese University, Lebanon \\ Correspondence: Abir R. Takieddine, Associate Professor, Faculty of Economic Sciences \& Business \\ Administration, Lebanese University, Lebanon. E-mai: abirtaki@hotmail.com
}

$\begin{array}{lc}\text { Received: April 12, } 2019 & \text { Accepted: May 7, } 2019 \quad \text { Online Published: May 24, } 2019 \\ \text { doi:10.5539/jms.v9n1p171 } & \text { URL: https://doi.org/10.5539/jms.v9n1p171 }\end{array}$

\begin{abstract}
The relationship between academia and industry is old. However, a twist is necessary to move from the traditional exchange of funding for research to the creation of long-term strategic partnerships of mutual benefit. The purpose of this study is to explore the effort made in Lebanon to forge the industry-academia link and to highlight the challenges faced. The researcher relied on both secondary and primary data. A review of the literature is made to set the theoretical framework regarding the need for creating strategic partnerships between academia and industry and its impact on sustainable economic growth. The researcher distinguished strategic partnership from the conventional exchange of research for funding approach. Moreover, she described the lessons learned from international experiences. Primary data are collected about Lebanon through interviewing key actors both in the industry and in academia. The study revealed that Lebanon realized several years ago the need to link academia to industry, several actors took measures to facilitate the collaboration. However, some measures did not reach their full potential yet due to some challenges. The author suggests few recommendations to overcome these challenges and strengthen the academia-industry collaboration.
\end{abstract}

Keywords: academia, industry, Lebanon, partnership, research, sustainable economic growth

\section{Introduction}

\subsection{Problem and Relevant Scholarship}

The collaboration between academia and the industry existed long ago and was mainly under the form of exchanging funding for research where industrial institutions provided researchers with the funds needed to conducts their research. However, the market is becoming more competitive worldwide because of the globalization that reduced distances and boundaries. The relationship between the university and the industry needs a transformation to create new forms of strategic partnerships that go beyond the traditional exchange of research for funding. In a knowledge driven economy, industries depend more and more on competent, innovative human capital. "A large number of countries are incorporating science, technology and innovation in their national development agenda, in order to make their economies less reliant on raw materials and more rooted in knowledge" (UNESCO, 2015, p. 5).

Partnerships between universities and the industries could take several forms such as collaborative research, onsite co-location, an access to world-class talent, as well as continuous professional development (Destler, 2008). Universities could expand technology transfer to the industry through patenting and licensing of faculty inventions, or creating "spinoff" firms to commercialize the faculty inventions (Mowery, 2010). However, a successful technology transfer system requires more than that, it necessitates the creation of an institutional framework that provides incentives for both sides (academia and industry) to overcome their differences and start exploring the existing potentials.

\subsection{Research Question and Hypotheses}

The problem could be reformulated as follow: the relationship between academia and industry is old. However, a twist is necessary to move from the traditional exchange of funding for research to the creation of long-term strategic partnerships of mutual benefits.

The purpose of this study is to explore the effort made in Lebanon to forge the link between industry and academia and to highlight the challenges faced. How far has Lebanon progressed on the way towards building 
strategic lasting partnerships between academia and the industry? What types of challenges exist and how to overcome it?

The researcher proposes the following hypotheses:

- Lebanon has realized the importance of creating strategic partnerships between academia and industry.

- Several initiatives took place to create stronger links between academia and industry in Lebanon.

- Lebanon is facing some challenges and more could be done to further link academia to practice.

\subsection{Importance of the Problem}

The research topic is important since the Lebanese economy is suffering from high unemployment rates and low GDP growth rates. The study suggests that building successful partnerships between academia and the industry will be an important factor in the revival of the Lebanese economy. Therefore, exploring and describing the current status is crucial to be able to recognize strengths and weaknesses to be able to formulate future policies.

\subsection{Research Design}

To answer the research question, the researcher will rely on both secondary and primary data. A review of the literature is necessary to set the theoretical framework regarding the need for creating strategic partnerships between academia and industry and its possible impact on sustainable economic growth. It is necessary to distinguish strategic partnership from the conventional exchange of research for funding approach as well. Moreover, Lebanon could benefit of the described lessons from international experiences. To explore the situation in Lebanon, primary data are collected through interviewing key stakeholders both in the industry and in academia.

\subsection{Research Sections}

This research is subdivided into an introduction, the adopted methodology, the theoretical framework based on literature, lessons from the international experiences, and the findings about the Lebanese experience, a conclusion with limitations and recommendations, and a bibliography.

\section{Methodology}

In this section, the author will argue for the methodology she adopted to answer the research question (Creswell, 1994).

\subsection{Research Approach}

This research adopts the constructivism approach which considers that social phenomena and their meaning are continually being accomplished by social actors. It will therefore describe the phenomenon of building strategic partnerships between academia and the industry in Lebanon and its reflection on research through the examination of the effort made by different actors. The researcher considers that truth is formed based on social interaction; she therefore adopts the interpretivism approach to research. Thus, she will identify different actors and describe their role in building the strategic partnerships.

To answer the research question, a deductive approach is followed. In the coming sections, the researcher will build a theoretical framework advocating building strategic partnerships between academia and industry to boost economic growth before observing the Lebanese case. The framework explains as well the structural reform necessary to shift from the traditional funding in exchange of research towards strategic academia/industry partnerships.

The research is qualitative in nature. It aims to provide a deep understanding of the phenomenon in question. It deals with how actors in question give meaning to their experiences. To ensure credibility, the researcher used triangulation i.e. tried to understand the phenomenon in question by using different theories and different sources of data for a more complete understanding.

\subsection{Research Data}

Both primary and secondary data are used. We used secondary data to describe the different measures taken around the world as well as in Lebanon to support academia/industry collaboration. Moreover, secondary data were collected to describe international success and failure stories to draw lessons.

To collect primary data, the researcher used the interview technique. Interviewing is a primary research technique; the researcher may choose to conduct face-to-face interviews, webcam interviews, telephone interviews, email interviews, or instant messages/chat interviews. We opted for the first type since the face-to-face interview allows the interviewer to see and hear social cues, probe and adapt the questions based on 
the respondent's answers. In few cases, the face-to-face interview was replaced by a phone interview due to the tight schedule of the interviewed. Moreover, the interviews were semi-structured based on a predetermined set of open questions with the opportunity for the interviewer to explore particular responses further. This type of interviews is suitable for exploring and describing phenomenon. An interview guide was prepared ahead of time which is an informal group of topics and questions that the interviewer could ask differently to seven actors.

\section{Theoretical Framework Based on Literature}

In this section, the researcher will rely upon existing literature to construct the theoretical framework necessary to build this deductive research.

\subsection{Benefits of Creating Long Term Strategic Academia/Industry Partnerships}

The concept of university-industry partnership is not new. Back to the late 19th century, the German pharmaceutical firm, Bayer formed relationships with universities (Bower, 1993). During World War I, the National Research Council of the United States had got together scientists in the research-oriented universities with those in industries to support the war effort (Rast et al., 2012). However, such partnerships were not very frequent. Nowadays, and because of the increasing influence of knowledge on economic growth, creating more and more partnerships is vital to any economy.

Globalization and the pressure of international competition are dissolving boundaries between nations, institutions and disciplines, creating a disturbed knowledge production system that is increasingly global (Saleh, 2002). The prosperity of a nation is based more and more on its ability to mobilize and exploit knowledge-intensive assets. In a global economy, regions seeking to compete more effectively have to build soft structures that support knowledge creation and enable firms to strengthen a region's capacity for knowledge creation and innovation (Cairney, 2000). Policymakers in developed countries started to formulate laws and regulations governing the exploitation of Intellectual Property (IP) to enhance the contribution of a national university system in industrial innovation (Mowery, 2010). According to Cairney (2000), this approach to regional development requires an environment of trust between the public and private sectors and between universities and the regions.

On one hand, universities are searching for new ways to remain a key player in the knowledge economy. Thus, they need to generate more funding for their very costly research. Furthermore, collaboration offers student and faculty the chance to solve practical problems and generate more employment opportunities for fresh graduates. Additional fund raising was a primary reason behind the collaboration of universities with the industries since funding from the industries involves less bureaucratic work compared to public funding. However, there is a huge difference between building a strategic partnership between universities and firms and between the simple exchanges of funding for research. Fundamentally, a university must view companies as partners in its research and education mission, not simply as an alternative revenue source.

On the other hand, firms are facing fierce competition and need to survive in a fast-changing environment characterized by fast technological progress. They are increasingly realizing that they cannot exclusively rely on their internal Research \& Development (R\&D) to successfully innovate. Forming partnerships with universities allows companies to access an enormous pool of skills and talents. Thus, universities could be considered a strategic partner for firms in the industry offering them the access to highly trained students, faculty, facilities, and new technologies. Industrial firms might use partnerships to build their reputation and image as well (Fombron, 1996).

The capacity of universities to adapt and play a bigger role in the global knowledge production is crucial to define their role in the national economy. Universities were historically a place where knowledge was sought by an elite few. It was protected and passed on to restricted communities. However, universities are now expected to provide the regional communities with knowledge, research and development activities. Thus, the issue of strategic partnerships between universities and industry becomes vital. Universities are expected to tell their academics to focus more on diversifying into profitable business. They are expected to develop links with businesses to boost their institution's income. Researchers have to prove that their research has an economic impact outside of their own institution. Defining success in academic technology transfer depends on defining what outcomes are desired, then tracking and measuring performance using metric models in the light of those desired outcomes (Rast et al., 2012).

Consequently, universities have the potential to act as strong drivers of growth by educating people with high skills in research and by commercializing and applying new knowledge to enhance prosperity and quality of life (WIPO, 2003). This requires an integrated innovation system of research centers, universities and 
businesses/industries.

\subsection{Necessary Structural Reform}

Creating strategic partnerships between universities and industries necessitates a relationship structural reform since technology transfer is only the top of the iceberg (Perkmann \& Salter, 2012). Rather than simply licensing the invention, it is more beneficial for companies and universities to collaborate throughout the whole life cycle of the innovation project.

Universities could take the lead to build new forms of partnerships with the industry if they recognize businesses as a major participant in the knowledge-based economy. Solving real problems in a business context is becoming the trend to create knowledge. The structure of the university has to encourage life-long learning opportunities, innovation, applied knowledge, and serving the community (B-HERT, 2012). Besides teaching and research, universities need to play a role in their community (Hamnetts, 1999). Measuring the success of a university will be based not only on the quality of its teaching and research, but also on its contribution in the region's social, economic, and cultural development (Cairney, 2000).

The reform in question could take place if business leaders and professionals are appointed more and more in the planning committees, courses accreditation committees, program design committees, and advisory boards of universities and are more involved in the content and delivery of courses. Introducing professional doctorates that provide post graduate training that is strongly connected to the needs of the industry is important, in addition to flexible programs to allow working students to pursue their education.

The success of these partnerships depends heavily on people. The university has to assign the responsibilities to people who have industry experiences, are multidisciplinary, can easily cross boundaries, are bridge-builders, and are capable of building and managing partnerships. The whole story starts by universities offering its faculty and staff the chance to meet company researchers and executives. To build a generation of faculty who strongly understands the industry, the university should encourage professors to work in industry and invite industry researchers to teach. It should encourage multidisciplinary academic programs and promote the engagement of the industry in it.

\subsection{Challenges Faced}

Despite the many benefits universities receive out of the collaboration with the industry, partnering with the industry does not come naturally.

Building a successful collaboration between universities and companies poses many challenges of which two are the most common: the degree of openness and the time horizon (Perkmann \& Salter, 2012). Academic science is open in nature compared to firms that tend to protect technologies used. Moreover, academic research tends to focus on long term challenges whereas the industrial Research and Development is driven more by day-to-day problem solving.

The choice of the best format of collaboration between universities and firms depends on the goals and capabilities of both partners. To be able to commercialize the research results, several ways are available for universities such as technology licensing, establishing start-up companies, supporting students venture programs, and establishing incubators.

\subsection{Secrets of Building Successful Partnerships}

To build visionary partnerships, it is necessary to redefine the role of the research university as discussed earlier. "The role now extends beyond teaching and public service research to tackling key social challenges and helping drive economic growth.... The University of the 21 st century should be viewed not just as a generator of ideas but as a source of knowledge and competence that can benefit society" (AISBL, 2012, pp. 11-12).

The university has to become the leader to ensure the launching and success of such partnerships. It needs to set the issue as a strategic priority and make the goals clear to all faculty members and has to provide them with incentives to engage with the industries and to offer them needed resources. There is a need for long-term strategic partnerships with built-in flexibility to increase the chances of success. Long-term strategic alliances focus on the creativity of the university and its ability to produce future innovations the industry could carry to the market; innovations that benefit the society for the coming ten years.

To increase the chances of a successful partnership, the university and the industry should start by sitting together to assess the academic strength of the university as well as the research competencies of the industry. Then, they should set together the research interests common to both. Moreover, they need to understand the different types of possible partnerships (AISBL, 2012); starting by the transactional partnerships that are not 
very interactive in nature such as teaching a course that might lead to bigger cooperation in the future, operational partnerships for one to three years on a research project with a particular R\&D division or lab, and strategic partnerships that runs from five to ten years that need a board and a flexible agreement that could generate knowledge that influences the university future research and teaching and the company's strategy. It is needless to say that a successful lasting partnership has to be a win-win situation.

Universities should not insist on protecting the IP that comes out of the research since the major benefit of this common research to the university is rather its impact on its teaching and the knowledge it gave the university from the industry-based projects (Destler, 2012). "The most fruitful partnerships take time to bear fruit" (AISBL, 2012, p. 11). Partners should not focus on the quantity of the output; they should rather focus on its quality. Thus, universities should not set artificial metrics to measure the output since it can fail to capture the unanticipated benefits that grow when a strategic partnership is built on trust.

\subsection{International Success Stories}

An interesting example of a long-lasting partnership is the Calit2. The partnership was initiated in 1999, when the State of California represented by its governor agreed on a partnership with the 10-campus University of California and the industry to boost the cooperation among all these stakeholders and increase the benefits to the society (AISBL, 2012). The Calit2 project created more than 25 spin-outs from the university research and established the first nanotech classroom facility on campus in San Diego shared by more than 60 companies. Furthermore, Caltit 2 created more than $\$ 100$ million in funding from over 300 industrial partners since 2000, in addition to $\$ 600$ million federal research funding. It also helped researchers win nearly 1000 federal, state, and non-state, industrial and international grants.

The IBM $\$ 90$ million nanotechnology center created in 2011 in Zurich is another example. It resulted of a partnership between IBM and the Swiss Federal Institute of Technology and lead to the foundation of the Binnig and Rohrer Nanotechnology Center as a cornerstone of a 10-years strategic partnership seeking to advance energy and information technology. IBM has been working for the past 20 years with the Imperial College London as well; a strategic alliance dealing with issues in digital economy (AISBL, 2012).

SIEMENS has presently long-term strategic partnerships with eight universities; four in Europe, two in China, and two in the US (AISBL, 2012). Nokia is collaborating with Aalto University in wireless technologies and multimedia technology research. It partnered with the UC Berkeley ass well to improve traffic circulation (AISBL, 2012). Moreover, Intel and IDA Ireland funded the UCD Technology Research for Independent Living Center.

The French pharmaceutical company, Servier, invested $€ 7.5$ million in partnership with the University College Dublin (UCD) to establish the UCD Servier Center for Translational Medicine (Destler, 2008).

Finally, ATC21S (Assessment and Teaching of $21^{\text {st }}$ Century Skills) was established in 2008. It is a partnership between Microsoft, CISCO and INTEL with the University of Melbourne costing \$2.5-3 million (AISBL, 2012). The partnership focuses on the critical skills needed in a global knowledge economy and has a big impact on teaching. It managed a very complex global academic research effort across 60 research institutions to develop computer-based collaboration and problem-solving tools to assess skills that will form the basis for new curricula.

\section{Measures Taken Worldwide to Forge Stronger Academia/Industry Links}

\subsection{In the United States}

The Bayh-Dole Act of 1980 is considered among the most influential initiatives in the United States. The act has been cited as an important factor in the competitive revival of the US economy during the 1990s (Mowery, 2010). The Act did not legalize anything that was until that time forbidden since US universities had long been active in patenting. However, the Act is cited because it simplified the process through which US universities could obtain patents on publicly funded research results and retain the royalties. This law produced considerable results for the US economy since it increased the patents filed by universities, generated millions of royalties, many start-ups and spin-offs (WIPO, 2003).

The act is considered part of a broader move in the US policy towards stronger intellectual property rights since a narrow-minded focus on licensing as a primary or only channel for technology transfer is not enough. The Act had another major impact since it inspired many governments starting the 1990s to issue laws and policies to promote the collaboration between the university researchers and the industry (Mowery, 2010). The Organization for Economic Cooperation and Development (OECD) has documented different practices in 13 member countries (WIPO, 2003). 


\subsection{In Europe}

To boost the innovation capacity in Europe, the European Union adopted in October 2010 a roadmap named Innovation Union (Destler, 2008). This roadmap proposes 34 measures referred to as "commitments" to be implemented to improve the conditions of operation of scientists, researchers, entrepreneurs and companies. The roadmap aims at removing the barriers that deter businesses from transforming its research into new products and services.

Moreover, the European Union Council of Minister endorsed in November 2011 seven "Principles for Innovative Doctoral Training" and called on Member States and universities to link national funding to these principles (Destler, 2008). The principles emphasized the exposure to industries, interdisciplinary research options, and the possibility for international networking.

In addition, the European Commission (commissioner for Research, Innovation, and Science) launched in July 2012 the "Reinforced European Research Area Partnership for Excellence and Growth" to create a single market for knowledge across Europe (Destler, 2008). The Commission is awarding universities in Europe the "HR Excellence in Research" logo for implementing the European Charter for Researchers and the Code of Conduct for recruitment of researchers (Destler, 2008).

To be able to implement the European Research Area ERA, the European Union has, from 2014 onwards, adopted a new funding instrument for European research and innovation; it is the Horizon 2020 (Destler, 2008). Horizon 2020 is important because it brings all the European funding for research and innovation under one roof and gives greater importance to innovation and economic impact.

\subsection{In Australia}

In Australia, the Business/ Higher Education Round Table (B-HERT) a non-profit organization was established in 1990 to strengthen the relation between business and higher education. B-HERT considers that there is a vital challenge in Australia to set the scene for a steady transformation in industry/business-university relationship and interaction (Business/Higher Education Round Table, 2002).

Earnest and Young conducted in 2012 an industry-wide survey of the main forces impacting the higher education industry globally and locally, and the opportunities, challenges and implications for Australian universities (Ernest \& Young, 2012). According to the survey, to increase its impact, universities need to adopt new teaching and learning delivery mechanisms, a diffusion of channels to market, and stakeholder expectations. Some universities will create new products and markets that merge part of the education sector with other sectors. The survey concluded that the dominant university model in Australia distinguished by a broad-based teaching and research institution supported by a large asset base and a large mainly in-house back office will prove unviable in most of the cases within the next 10-15 years.

\subsection{In the Western Pacific}

The education system in the Western Pacific is highly nationalized and linguistically divided unlike the more integrated systems in North America where everybody speaks English and in Europe where most researchers speaks English (Maslen, 2014). Despite that, the number of university partnerships is on the rise. This is helping institutions boost the quality of their research and is setting a trend of investing in academic and industrial research and development.

\subsection{In the Arab Countries}

The contribution of the Arab Countries in the area of scientific publications and registered patents is negligible. Dr Sultan Abu-Orabi, secretary general of the Association of Arab Universities (AARU), states the problem in Arabian higher education as follow: "The Arab world... faces a host of hurdles when it comes to higher education and scientific research including a lack of clear focus in research priorities and strategies, insufficient time and funding to meet the research goals, low awareness of the importance and impact of good scientific research, inadequate networking opportunities and database, limited international collaborative efforts and brain drain" (ICEF, 2014, p. 1).

According to Mrad and al (2013), the majority of Arabs higher education institutions claim research objectives in their mission, while little budget resources are allocated for research programs. Moreover, research time in faculty agenda is decorative. It is more like filling gaps in between the productive hours and days dedicated mainly for teaching courses and administrative duties. The academic policies governing the recruitment and promotion in Arab universities are not reflecting stated missions and national or regional priorities. 
In March 2014, the 22 Arab countries signed off on a regional strategy for Science, Technology and Innovation (STI). The strategy aims to enhance education and research and increase financial support for research and development; it focuses on 14 priority areas of research and is supported by a new online platform for Arab science and technology (Sawahel, 2014). Among the major challenges to be dealt with by the STI is the research institutions in the Arab world are not sufficiently serving the needs of neither industry nor society (ICFE, 2014).

To conclude this section, the success of technology transfer requires changes at the institutional as well as national levels. At this stage of the research, it is crucial to focus on the Lebanese experience to answer the following questions: How far has Lebanon progressed on the way towards building strategic lasting partnerships between academia and the industry? What types of challenges are the different players facing and how could they overcome it?

\section{The Lebanese Experience: Findings and Analysis}

The Lebanese economy is facing critical challenges at the levels of employment and sustainable growth. Linking academia to industry could help Lebanon face its under-performing economy by building upon the skills of its qualified human capital to produce research that answers local socio-economic needs.

However, in a study performed by the National Council for Scientific Research (NCSR) in Lebanon in 2009, it was clearly stated that although the level of educational achievements is high, "Lebanon suffers from low levels of productivity, innovation, competitiveness and a very low level of networking and connectivity between its economic, educational and professional organizations" (NCSR, 2009, p. 32).

\subsection{The Industrial and Academic Environments in Lebanon}

Lebanon has witnessed three main waves of interest in supporting the private sector as a main engine to economic growth, in the 1990s, in early 2000s and in 2005 (MoET, 2014). In the 1990s, the government led the efforts to help enterprises recover from the civil war through the enacting of new laws, creating economic zones, establishing the Investment Development Authority of Lebanon (IDAL) in 1994 and the reactivation of the Beirut Stock Exchange in 1996. In early 2000s, the Central Bank, supported by many foreign development agencies offered long-term subsidized loans to selected industries. Kafalat, Lebanon's credit guarantee scheme was created by a joint effort of 50 Lebanese banks and the National Institute for the Guarantee of Deposits.

Since 2005, the focus shifted in Lebanon to support the small and medium size enterprises (SMEs) focusing on entrepreneurship, paralleled by a similar interest worldwide. New players mainly from the private sector and the NGOs entered the scene and many entities such as Bader and Berytech were established and actively worked on funding, supporting, and developing entrepreneurs. According to the Lebanese Ministry of Economy and Trade, SMEs constitute around 94\% of enterprises in Lebanon and employ half of the workforce (MoET, 2014). However, these SMEs face many challenges holding back its productivity and ability to compete in the international market. One of the main challenges is the delay in the shift to the knowledge economy mainly because of poor infrastructure and insufficient expenditure on R\&D. The budget given to innovation is low despite the availability of competent human capital.

Higher education in Lebanon is the oldest in the region. It dates back to 1886 when the American University of Beirut (AUB) was established followed by the Université Saint Joseph (USJ) in 1875. Qualified human capital is abundant in Lebanon and the population is multilingual and open to cultural diversity. Currently, the number of higher education institutions is relatively high (around 40 including the Lebanese University - LU—as the only State University) and most were established in the late nineties. Nevertheless, most of these institutions are teaching rather than research oriented with three only (AUB, LU, USJ) having doctoral schools in addition to few joint Ph-d programs with international schools.

According to the European Commission (2012), inter-university cooperation is weak within the country and reliable financial information about universities is not available. Moreover, direct government spending on higher education is below $0.5 \%$ of GDP and below the $1 \%$ average of the OECD countries.

\subsection{Sources of Funding}

\subsubsection{The National Council for Scientific Research}

The Lebanese State funds research through the National Council for Scientific Research (NCSR) established in 1962. The Council totally or partially finances projects that are implemented in its affiliated centers or in collaboration with the Lebanese University or the private universities. It has funded since 1998 more than 1000 projects with a total budget of 6 billion Lebanese pounds (NCSR, 2009) and offered 450 PHD scholarships in Lebanon and abroad (NCSR, 2017). Students studying at the LU followed by AUB and USJ then by other 
institutions received between 40\%-79\% of the funds depending on years (between 2002 and 2015) (NCSR, 2017). Although the law stipulated that $1 \%$ of the national budget should be allocated to research, this has never been the case. The Council faces a limited budget as well as institutional constraints such as a limited potential to expand specialized centers.

\subsubsection{The Industrial Research Institute}

The institute was established in 1953 as a nonprofit institute, declared public in 1955 then linked to the Ministry of Industry in 1997 (IRI, 2017). It has administrative and financial autonomy to conduct industrial research and scientific testing to support the Lebanese industrialists and the national economy. It comprises 14 labs and is a member in several international organizations. Moreover, the Institute provides training and consultancy for laboratories' accreditation on national, regional and international levels.

\subsubsection{The Central Bank of Lebanon}

To encourage research with an economic impact, the Central Bank of Lebanon issued circular No 313 on January 14, 2013. The circular states that the Bank will grant credits to banks "for research and development works in the productive sectors, conducted jointly by productive institutions in the Lebanese private sector and any university, research center or business incubator, with the purpose of developing existing products or creating new ones, provided the reimbursement period of the loan principal does not exceed ten years, starting from the expiry of a grace period ranging between two and four years from the loan granting date" (BDL (1), 2013). It also issued circular No. 331 in August 2013 to encourage the financing of startups, accelerators, and incubators through banks and financial institutions (BDL (2), 2013).

Moreover, it organized in 2014, 2015, and 2016 the BDL Accelerate conference in Beirut. The conference was attended by 25000 local and entrepreneurs, investors, and professionals in 2016 and was the biggest in the MENA region.

According to Mr. J. M., the Executive Director of Training and Development at the Central Bank, "the gap is evident between the higher education sector and the market in Lebanon regarding the graduates' competencies. However, this gap is being reduced because of the internship periods students spend in operating institutions" (J. M., 2017, Personal Interview). The Central Bank is contributing to reduce this gap by receiving a large number of students as trainee each year. Moreover, according to Mr. J. M. "the Central Bank considers that SMEs in Lebanon need training, technical and financial support to be able to operate efficiently, transparently and with good governance. They also need technical and financial support to innovate and invest in RD\&I.” Therefore, it took the initiative to help by issuing many circulars and organizing the Accelerate Conference.

\subsubsection{The European Union}

TEMPUS is an inter-university cooperation program created by the European Union (EU) to help the partner countries in their effort to modernize and reform their system of higher education. The National Tempus Office of Lebanon located at the Ministry of Education and Higher Education in Beirut was established in 2003. The National ERASMUS + Office is the legitimate successor of the former national TEMPUS office and coordinates and implements the ERASMUS + programs in Lebanon. The office has funded 58 projects to date. Projects usually involve beneficiary home institutions as well as institutions from other involved countries and last for 12 to 36 months. The subjects covered a wide range of issue such as the development of the students support services, creation of interdisciplinary programs, establishment of new masters' programs and doctoral schools, quality assurance, institutional effectiveness, university management, leadership and innovation.

According to Dr. K. B., who is the Vice President for International Affairs at the Modern University for Business and Science (MUBS) that has been a participant in several projects funded by the Office, "the higher education sector in Lebanon has become more aware of the importance of research administration and of establishing links with the industry as part of quality in higher education and responsibility towards learners. This is partially due to the many activities that were carried out during the implementation of the several projects funded by the TEMPUS/ERASMUS + Office and the regular events held by the Lebanese partner higher education institutions which involved participants from governmental agencies, socio-economic sectors, and employers. These projects enhanced the relationship with the labor market and provided opportunities for students to find internships and jobs (K. B., 2017, Personal Interview).

\subsection{Reforms at the National Level}

Several measures have been taken at the national level by different authorities to encourage the collaboration between the higher education sector and the industries in Lebanon. 


\subsubsection{The Lebanese Industrial Research Achievement Program}

Back in 1997, the Lebanese Industrial Research Achievement Program (LIRA) was established. It is the result of the cooperation between the Association of Lebanese Industrialists, the National Council for Scientific Research (NCSR), some universities, with the support of the German-based public institute foundation Friedrich Ebert Stiftung. LIRA first initiated an annual forum the Conference of Industrial Research and Development and the Exhibition of Industrial Research Achievements. This is an event that provided a chance for industry, academia and research centers, public and private, to get together and exchange their research findings. The conference has assisted in the creation of new production lines, new firms, and updated engineering courses in some universities (LIRA, 2018). Funding is always a challenge; LIRA is always working on attracting more local and international sponsors to support the realization of its objectives.

Mr. N. G., the Vice President of the Lebanese Industrialists Association, believes that "the Lebanese industrial sector could benefit tremendously from the collaboration with the universities. The Lebanese Industrialists Association has a firm belief in such collaboration and supports (LIRA) financially. The Association is always open to collaborate with universities and research centers in Lebanon in projects with positive impact on productivity" (N. G., 2017, Personal Interview).

\subsubsection{The Patent Law and the Intellectual Property Protection Office}

The Lebanese State enacted a new Patent Law in August 2000 that provides a patent protection for inventions. The Law conforms to the Trade-Related Aspects of Intellectual Property Rights (TRIPS) Agreement according to the World Intellectual Property Organization (WIPO) assessment in July 2012.

The Arab Center for the Development of the Rule of Law and Integrity (ACRLI) with the assistance of the Consultation and Research Institute performed a study about the Intellectual Property Rights in Lebanon in 2009. The sample was composed of 165 respondents coming from the private, public, and legal sectors. The study revealed that the respondents are not very familiar with the IP law and regulations and are not very satisfied with the Office (ACRLI, 2009).

\subsubsection{The Science, Technology and Innovation Policy (STIP)}

The Science, Technology and Innovation Policy (STIP) was formulated in 2006 by the NCSR. It aims to gradually transform Lebanon into a knowledge-based society and to bridge the gap between the university research and tangible economic and social applications is large (NCSR, 2009). The STIP considers that "without partnership, dialogue, and mutual understanding between government and companies on the one hand, and scientists, engineers, universities and institutes on the other hand, the gap that inevitably exists between science efforts and their useful and tangible economic and social applications will not be bridged." (NCSR, 2009, p. 58) Thus, the STIP "aims to represent a change in the culture and in attitudes" (NCSR, 2009, p. 61).

The STIP was not fully implemented due to financial constraints imposed by politics and economics. However, the NCSR was able to at least adopt the STIP priorities in the grants offered to finance research projects and in calling on Lebanese universities for the joint establishment of Associated Research Units in priority areas defined by STIP.

\subsubsection{The National Strategy for Education}

The national strategy for education in Lebanon was drafted in 2007. Among the reforms recommended in the strategy is the promotion of university-enterprise cooperation, the support of research as well as the reinforcement of cooperation among local universities in research activities (LAES, 2006).

The strategy identified weaknesses in the Lebanese higher education system since the existing frameworks do not fully prepare graduates to become innovative human capital capable creating knowledge and adding to economic growth. Despite the importance of this strategy, it is unfortunately not fully implemented yet.

\subsubsection{The (IDEAL) Project}

In 2012, the Tempus program funded the "Innovation and Development of Academic-Industry Partnerships through Efficient Research Administration in Lebanon" (IDEAL Project, IDEAL, 2017). The project involved 9 participants from Lebanon in addition to participants from the United Kingdom, Austria, Spain, Italy and Greece. The project duration was 36 months and the budget $€ 904,877.49$.

According to Dr. K. B., the Vice President for International Affairs at MUBS who is a participant in the project, the impact of the IDEAL project is perceived to be tremendously positive by MUBS. "Academic and administrative staffs were trained on developing and building capable research support systems, establishing links with the industry, establishing professional structures between government, academia, and industry to 
support Research, Development, and Innovation (RD\&I)" (K. B., 2017, Personal Interview). Among the various benefits of the project is the establishment of a research administration office. However, and always according to Dr. K. B., the political instability in Lebanon negatively reflected on the project since "most of the European Union partners were not able to come to Lebanon, as a result, most of the training sessions were videotaped and were not as interactive as we had wished for. To overcome this, the IDEAL coordinators served as moderators of all sessions and contributed with examples from their own work and with local practices and examples".

\subsubsection{The Ministry of Economy and Trade Roadmap 2020}

The Ministry of economy and Trade proposed a Strategy roadmap for SMEs to the year 2020. The roadmap is composed of several initiatives to develop the SMEs (MoET, 2014). To enhance the capabilities and innovation capacity, the ministry emphasized the need to ensure stronger ties with academia, training and R\&D centers and to refocus budgets in R\&D to additionally develop the capabilities of the SMEs in main sectors and create a comparative advantage for Lebanon.

To conclude this subsection, several measures were implemented at the national level to increase the collaboration between academia and practice in Lebanon. Some of these measures were fully implemented, others partially. According to Dr. K. C., a member at the Technical Committee at the Ministry of Education and Higher Education in charge of supervising the abidance of higher education institutions in Lebanon by the Ministry's standards, "bureaucracy is hindering the full implementation of several measures" (K. C., 2017, Personal Interview). Dr. H. A., the TEMPUS/ERASMUS + Office Coordinator assistant summed up the main challengers facing Lebanon regarding the collaboration between academia and industry by saying "the collaboration between universities in Lebanon and the productive sector becomes harder because this sector, mainly composed of SMEs, is not well organized. Most firms lack the culture of RD\&I and are not used to collaborate with universities" (H. A., 2017, Personal Interview). Dr. H. A. considers that the Universities Association of Lebanon (UAO) comprising 19 Lebanese higher education institutions created few years back will help facilitating the cooperation among universities and between them and the industries. Moreover, the successful implementation of any measure is, according to Dr. H. A, always dependent on serious and continuous follow-up.

According to Dr. J. A., the Director General of Higher Education in Lebanon, the Ministry is putting a lot of effort to enhance networking between universities in Lebanon since networking facilitates the collaboration with other stakeholders such as industries. However, despite the efforts made by the Ministry and supported by the European Union, the level of networking among universities in Lebanon is still low.

After considering the reforms that took place at the national level in Lebanon, let us at this stage consider the changes taking place at the institutional level.

\subsection{Reforms at the Institutional Level}

An extensive overview of the local newspapers and the Lebanese universities websites revealed many agreements signed in the last few years between the universities themselves and between them and universities/institutions abroad mainly to teach joint programs and exchange knowledge. The researcher decided to elaborate on few agreements she considers of importance to answer the research question and give an idea about structural reforms that took place at the institutional level in Lebanon.

\subsubsection{The National Center for Studying the Side Effects of Medications}

The Center was inaugurated in September 2016; a collaboration between the faculties of medicine, dentistry, health and pharmacy at the Lebanese University and the Lebanese Ministry of Health. The Center tests the quality of food, water, chemicals, medication and medication side effects and has been an active partner with the ministry of health in the campaign of food safety launched by the ministry. Currently, the Center is working in collaboration with researcher from private universities as well as research centers on a national scale project to assess the contamination of water, food, and air with cancerous materials.

According to the director of the Center, Dr. A. N., the Center has recently completed the needed requirements to receive the ISO 2015 and is about to complete a full map of air pollution in Lebanon in collaboration with several private universities and the Lebanese Agricultural Research Institute (A. N., 2017, Personal Interview).

Despite the importance of the achievements, and according to Dr. A. N., the Center is facing many challenges namely; the difficulty in cooperating with some ministries, a shortage in human resources and budget constraints hindering a faster and more productive operation. 
5.4.2 The Research, Documentation, and Publication Center at the Faculty of Economic Sciences and Business Administration at the Lebanese University

The Center was established in July 2016 and is responsible of the formulation of research policies for the faculty, the establishment of needed laboratories, adoption of research programs, organization of conferences and workshops, supervision of the faculty research and refereed journal, production of a useful database for researchers. It has a national role namely the calculation of major national economic indicators. It is supposed to conduct research for the Lebanese University, the public sector as well as the private sector and to create a research agenda for the faculty and more importantly to orient it to the local market needs to make it more relevant. Unfortunately, the center is not fully operating yet because of the budget and administrative constraints the University is facing.

\subsubsection{The AUB-USJ Memorandum of Understanding}

A memorandum of understanding was signed in January 2018 between the two universities for a mutually beneficial collaboration in several fields, including research, joint masters and/or PhD programs, and joint conferences (AUB, 2018).

According to Mrs. R.B., the Assistant to the Provost for Academic and Faculty Affairs at AUB, "AUB is strongly committed to serve its community through research and education. It continuously strives to adapt its curriculum to the market needs to be able to provide its graduates with the needed skills to compete in the job market. AUB strongly believes in the importance of producing research with great impact as well. Therefore, it has lately signed many agreements to strengthen its collaboration with various productive sectors and with the Lebanese community" (R.B., 2017, Personal Interview).

\subsubsection{The AUB-ASREN Agreement}

The AUB has signed, in February 2016, an agreement with the Arab States Research and Education Network (ASREN) that connects Lebanon to the global research and education community through the European Research and Education network GEANT (AUB, 2018). AUB now connects to GEANT through an ASREN link which provides a gateway for international research and education collaboration.

Moreover, AUB is currently working in collaboration with other universities in Lebanon to establish the Lebanese Education Research Network (LEARN) to facilitate research and education exchange.

\subsubsection{The AUB-Beirut Municipality Agreement}

The Office of Strategic Health Initiatives (SHI) at AUB has signed in October 2016 a memorandum of understanding with the Municipal Council of Beirut (MCB) to cooperate in establishing the "Beirut: Healthy City 2022 " vision with a clear and sustainable operational plan to achieve it (AUB, 2018). The agreement formalises collaboration involving capacity building at $\mathrm{MCB}$ health care facilities, direct technical assistance and action-oriented research.

\subsubsection{The AUB-Sin El Fil Municipality Agreement}

The Center for Public Health Practice (CPHP) at the Faculty of Health Sciences at AUB announced, in February 2018, the signing of a cooperation agreement with the Sin El Fil municipality in the framework of the "Sin el fil: a safer city, a healthier population" project, and the launching of the phase II of the Health and Development cooperation program (AUB, 2018).

AUB President reaffirmed in his speech the University's willingness to put its expertise, research, and technical and scientific resources to find suitable and sustainable solutions for challenges threatening people's safety and health" (AUB, 2018).

\subsubsection{The AUBMC-Phillips Agreement}

To strengthen its research capacity and leadership position in the healthcare sector in Lebanon and the region, the American University of Beirut Medical Center (AUBMC) signed in October 2016 a master research collaboration agreement with Phillips, making it the first scientific research agreement in Lebanon and the Middle East (AUB, 2018). The agreement presents a significant leap in promoting clinical, basic science research in favor of advancing patient care.

\subsubsection{The University Antonine-TICKET Lab-BMW Memorandums of Understanding}

Two Memorandums of Understanding were signed between TICKET Research Lab and BMW Group and the University Antonine (UA) in June 2017 (AU, 2018). TICKET Lab. is playing a major role in the development of technology transfer in accordance with the University Antonine research strategy as declared in its strategic plan (H 2020). The memorandums allow TICKET Lab to develop research in Data Mining and Anonymization, and 
Virtual Reality, with the IT Department and the Logistics Department at BMW Group. It also allows the university students to be engaged in internships at BMW Group. The memorandums reflect the commitment of all parties toward this cooperation that will have a profound impact on education as well as quality research.

\subsubsection{The LAU-UOB Agreement}

On June 2017, the University of Balamand (UOB) and the Lebanese American University (LAU) concluded an agreement to establish research and educational exchange programs and to promote the development of joint studies, research and training activities of mutual interest (LAU, 2018). Among several other topics, the research collaboration and exchange program will include Pharmaceutical Sciences, Biomedical Sciences, Basic Translational Sciences, Clinical Pharmacology, Molecular and Cellular Biology. Ultimately, the agreement will allow LAU together with UOB, to work together on developing Master's and Ph.D. programs tailored to their interests in the various scientific fields.

\subsubsection{The UOB-BPI Agreement}

The UOB and the Benta Pharma Industries (BPI) have recently entered into a cooperation agreement in the field of Therapeutic Biotechnology to train and develop capacities of UOB students at the Faculty of Health Sciences (UOB, 2018). The collaboration with BPI will provide UOB students with scientific and practical trainings concerning the latest technologies in Therapeutic Biotechnology in addition to developing mutual scientific research and cooperation.

\subsubsection{The BAU-LIRA Agreement}

In June 2012, the Beirut Arab University (BAU) signed an Agreement of Cooperation with the Lebanese Industrial Research Achievements Program (LIRA); an initiative to bring the universities and scientific research closer to industry and the industrialists' needs (BAU, 2018). The agreement aims at establishing industrial and graduate research projects between BAU and the industrial sector, exchanging information and experience, providing the necessary funding for the common activities, conferences and seminars, encouraging factories to welcome students for training in their labs, and seeking harmony between the university programs and the job market needs.

\subsubsection{The BAU-LU Agreement}

The BAU and the Lebanese University (LU) signed in October 2014 a five-year Academic and Research Cooperation Agreement in the fields of Engineering, Medical and Health Sciences, Environmental and Agricultural Sciences as well as in the Social Sciences and Arts (BAU, 2018). The Agreement aims to facilitate the exchange of faculty for teaching, research and supervision of theses, as well as the facilitation of postgraduate student transfers between the two universities, and the organization of conferences, workshops, seminars and training courses to build on the expertise at both universities.

\subsubsection{Mobarat El Oloum by the National Association for Science and Research}

The National Association for Science and Research (NASR) holds annually since 2004 "Mobarat Al Oloum", an event where Lebanese school students (grade 7-12) compete to design projects in robotics, environment, health sciences, physics, chemistry and astronomy. University students and professors from around Lebanon volunteer to form the judging committee. A total of 7000 young innovators participated since 2004 in over 2000 projects. To support innovators realize their projects, NASR has dedicated a section at its headquarters as a business incubator and has completed the registration of 25 patents with the ministry of economy and trade.

To conclude this section, several agreements were signed lately by several universities in Lebanon to enhance its collaboration with the market. This indicates that the reforms realized at the national level started to reflect at the level of the institutions. However, most of these agreements are recent and time is needed before we could fully evaluate its impact on education and research outputs.

\section{Conclusion, Limitation and Recommendations}

In this research, the author explored the effort made in Lebanon to create strategic partnerships between academia and industry. She adopted the constructivism and interpretivism approaches to research. The research is deductive and qualitative in nature; therefore, the researcher constructed a theoretical framework based on literature to build the study upon and collected primary data via interviews. To overcome the limitations imposed by its qualitative nature, and to ensure credibility, the researcher made sure to use triangulation.

The analysis of the findings leads the author to accept the research hypotheses namely; Lebanon has already realized the importance of creating strategic academia-industry partnerships and took several initiatives at the national and institutional levels. However, some challenges are facing Lebanon to fully succeed in its efforts. 
Therefore, if we consider that creating strategic partnerships between academia and industry requires networking, setting clear research and competencies priorities, establishing structures that facilitate collaboration, and nurturing the culture of perceiving the other as a strategic partner, we could conclude that Lebanon has started this long journey.

However, more effort is needed to reduce bureaucracy and corruption and create structures at the national and institutional levels to facilitate the collaboration between universities and industries throughout the whole life cycle of the innovation projects. The culture of innovation, flexibility, life-long learning, focusing on applied knowledge and perceiving the industries as a strategic partner needs to be nurtured more and more among the academics. The industries on the other hand, strongly dominated by SMEs are mostly family businesses that have no real understanding of what RD\&I could offer them and what universities could offer them in this respect.

In conclusion, despite the Lebanese political instability, corruption, and tight national budget caused by the critical national economic situation, the measures taken by different actors in Lebanon positively impacted the academia-industry collaboration. However, collaboration did not reach the level of creating long lasting strategic partnerships yet.

To move further and succeed in establishing long lasting academia-industry partnerships, the author recommends the different stakeholders to have persistence since establishing new cultures requires time. The new generations of both academics and entrepreneurs will value more and more the importance of collaboration and could take the lead to build successful partnerships. In parallel, the State needs to keep on developing the legal framework to match the needs of the different stakeholders by building necessary infrastructures.

\section{Acknowledgement}

This research is funded by the Lebanese University.

\section{References}

A.N. (2017). Personal Interview.

ACRLI. (2009). The intellectual property rights in Lebanon. The Consultation and Research Institute, Beirut, October.

AISBL, Science/Business Innovation Board. (2012). Making Industry-University Partnerships Work: Lessons from Successful Collaboration. Brussels: Belgium.

AU, Antonine University. (2018). Retrieved from http://www.ua.edu.lb

AUB, American University of Beirut. (2018). Retrieved from http://www.aub.edu.lb

BAU, Beirut Arab University. (2018). Retrieved from http://www.bau.edu.lb

BDL (1). (2013). Intermediate Circular 313 Addressed to Banks and Financial Institutions. Retrieved January 14, 2013, from http://www.bdl.gov.lb

BDL (2). (2013). Intermediate Circular 331 Addressed to Banks and Financial Institutions. Retrieved August 22, from http://www.bdl.gov.lb

Bower, J. (1993). Successful joint ventures in science parks. Long Range Planning, 114-120. https://doi.org/10.1016/0024-6301(93)90213-Y

Business/Higher Education Round Table (B-HERT). (2002). Greater Involvement and Interaction Between Industry and Higher Education. Australia: Melbourne.

Cairney, T. H. (2000), The role of universities in developing regional knowledge workers. Unpublished paper.

Creswell, J. W. (1994). Research design, qualitative and quantitative approaches. Thousand Oaks, CA, US: Sage Publications, Inc.

Destler, B. (2008). A new relationship between business and academia. Rochester Institute of Technology, Retrieved from https://www.rit.edu-preident-papers

Destler, B. (2012). Increasing US competitiveness: Building a new relationship between business and academia. HUFFPOST, November, 26

Ernest, \& Young. (2012). University of the future: A thousand-year old industry on the cusp of profound change. Australia.

European Commission. (2012). Higher education in Lebanon. Tempus. 
Fombrn, C. (1996). Reputation: Realizing value from the corporate image. Boston: Harvard Business Press.

H. A. (2017). Personal Interview.

Hanetts, A. (1999). The Universities and the Region: A Strategy for the Next 10 Years. Unpublished paper.

ICEF Monitor. (2014). Boosting science and technology collaboration among Arab States. Retrieved April 16, 2014, from http://www.monitor.icef.com

IDEAL. (2017). Retrieved from http://www.ideal4lebanon.orgIDEAL project official website

IRI. (2017). Retrieved from http://www.iri.org.lbIndustrial Research Institute official website

J. M. (2017). Personal Interview.

K. B. (2017). Personal Interview.

K. C. (2017). Personal Interview.

LAU, Lebanese American University. (2018). Retrieved from http://www.lau.edu.lb

Lebanese Association for Educational Studies. (2006). National Educational Strategy in Lebanon.

LIRA. (2018). Retrieved from http://www.liraprogram.com

Maslen, G. (2014). Asian Tiger Universities grow Research Collaboration. University World News, 313.

MoET (Ministry of Economy and Trade). (2014). Lebanon SME strategy: A Roadmap to 2020. Inventis.

Mowery, D. (2010). University-Industry Collaboration and Technology Transfer in Hong Kong and Knowledge-Based Economic Growth. Hong Kong Innovation Project (Report No. 1). https://doi.org/10.1057/9780230304116_2

Mrad, F., Hanafi, S., \& Arvanitis, R. (2013). Scientific production in the Arab countries. Working Paper series, ESCWA.

N. G. (2017). Personal Interview.

NASR, National Association for Science and Research in Lebanon. (2018). Mobarat El Oloum. Retrieved from http://www.sciencelb.org

NCSR. (2009). Science, Technology, \& Innovation Policy for Lebanon. UNESCO, Paris, April.

NCSR. (2017). Retrieved from http://www.cnrs.edu.lb

R. B. (2017). Personal Interview.

Perkmann, M., \& Salter, A. (2012). How to Create Productive Partnerships with Universities. MIT Magazine, June 18.

Rast, S., Khabiri, N., \& Senin, A. A. (2012). Evaluation Framework for Assessing University-Industry Collaborative Research and Technological Initiative. APBITM, Pattaya, Thailand. https://doi.org/10.1016/j.sbspro.2012.03.208

Saleh, N. (2002). Research management issues in the Arab countries. Higher Education Policy 15, Interational Association of Universities, Elsevier Science Ltd. https://doi.org/10.1016/S0952-8733(02)00015-6

Sawahel, W. (2014). New Arab strategy for science, technology and innovation. University World News, 313.

UNESCO. (2015). UNESCO science report: Towards 2030. UNESCO Publishing.

UOB, University of Balamad. (2018). Retrieved from http://www.uob.edu.lb

WIPO World Intellectual property Organization. (2003). WIPO Arab regional meeting on intellectual property as a power tool for economic growth. Amman, Jordan, June 1.

\section{Copyrights}

Copyright for this article is retained by the author, with first publication rights granted to the journal.

This is an open-access article distributed under the terms and conditions of the Creative Commons Attribution license (http://creativecommons.org/licenses/by/4.0/). 